Session 3213

\title{
Comparison of Students' Performance in Online and Conventional Sections of Engineering Thermodynamics
}

\author{
Geoffrey D. Silcox \\ Department of Chemical Engineering \\ University of Utah \\ Salt Lake City, Utah 84112
}

\begin{abstract}
Abstact
The effectiveness of online and conventional sections of engineering thermodynamics were compared by looking at (1) $\mathrm{ChE}$ and ME students' performance in subsequent thermodynamics courses, (2) two sections' performance on an identical final, and (3) $\mathrm{ChE}$ and ME students' grades. By all measures employed, there is not a statistically significant difference in the effectiveness of the two approaches. The two groups were not randomly chosen.
\end{abstract}

The students taking the online and conventional sections have a mean grades of 3.16 (four-point scale) and 3.08 in their subsequent thermodynamics courses. The statistically insignificant difference between the means is $0.075 \pm 0.832$ (95\% confidence level).

Two sections were given identical finals. The mean (200-point basis) for the online section was 144 while that for the conventional was 145 . Twenty-one students were in the online section and 59 were in the traditional section.

In making a comparison based on grades in the introductory course, the focus was limited to those $\mathrm{ChE}$ and $\mathrm{ME}$ students who took subsequent thermodynamics courses. For those two majors, the online and conventional students have mean grades of 3.33 and 3.16. The statistically insignificant difference between the means is $0.213 \pm 0.628$.

\section{Introduction}

I have taught parallel sections of online and conventional engineering thermodynamics for fours semesters. This paper compares the effectiveness of the two approaches based on scores on examinations, grades, and performance in subsequent thermodynamics courses. The data were collected in the semesters summarized in Table 1. 


\begin{tabular}{|c|c|}
\hline Fall Semester & Spring Semester \\
\hline 2001 conventional and online & 2003 online \\
\hline 2002 conventional and online & \\
\hline
\end{tabular}

Table 1. This paper compares the online and conventional sections listed here.

The content of the two sections is identical: thermodynamic properties, open and closed systems, equations of state, heat and work, the first law of thermodynamics, the second law of thermodynamics, the Carnot cycle, and an introduction to power and refrigeration cycles. Both sections use the same lecture notes, text, and homework assignments. Solutions to homework assignments and examinations are posted on the course website. The examinations for the online and conventional sections were taken with pencil and paper in a proctored setting.

The enrollments in the online and conventional sections are about 25 and 70 . The students are from four departments: chemical, civil and environmental, mechanical, and electrical engineering. The online students are usually local and about half take advantage of in-person office hours. In this sense the online section is not entirely online. I make extensive use of email and limited use of the telephone in answering the online students' questions. Students generally enroll in the online section because of conflicts with their class or work schedules.

The online course is presented using WebCT. I use the bulletin board, student-tracking, and quiz features. The bulletin board allows me to post announcements and to respond to students' questions. The students use it to arrange study groups and to help each other with the homework. The quiz feature is particularly important because it keeps students on schedule. There are 23 lectures. The corresponding 23 quizzes require a numerical answer and are configured to allow unlimited attempts during a one-week period. WebCT grades the quizzes and records the highest scores. The quizzes are designed so that the data in the problems are varied each time a quiz is accessed. The studenttracking tool allows students to view their scores on homework, quizzes, and examinations. A teaching assistant is given access to the tracking tool so that she can enter homework scores.

A number of other authors have studied online and conventional formats. Wallace and Mutooni ${ }^{1}$ compared the performance of students who experienced a web-based lecture and a traditional one. They found that the students taking the online lecture outperformed the others. Dutton et al. ${ }^{2}$ compared two large sections of an introductory class in $\mathrm{C}++$. They also found that the online group did better that the traditional lecture group, although students in the former were less likely to complete the course. Haag and Palais ${ }^{3}$ found no significant difference between the two groups in a fiber optics course. Nguyen and Paschal ${ }^{4}$ randomly split the students attending an "instructional module" on ultrasound in half and again found no statistically significant difference between the two 
groups.

In this study involving engineering thermodynamics, I detect no statistically significant difference between the online and traditional formats. From talking to students, I find that those who have the option of taking a traditional course prefer to do so.

\section{Comparison of Grades in Subsequent, Junior-Level Thermodynamics Courses}

One way to compare the two approaches is by looking at performance in subsequent, junior-level thermodynamics courses. Only chemical and mechanical engineering majors are required to take a second course. The former take Chemical Engineering Thermodynamics (ChE 3853): principles of physical and chemical equilibria with applications in the chemical process industries. The latter take Thermodynamics II (ME 3600): analysis of applied thermodynamic systems, including: gas power cycles, vapor power cycles, combined power cycles, refrigeration cycles, air conditioning cycles, gas mixtures, air-water vapor mixtures, chemical reactions, combustion, and chemical and phase equilibria.

The weakness in this comparison is the limited number of online students who take a second thermodynamics course. Of the 61 students who completed the online sections listed in Table 1, only 7 completed a second thermodynamics course. Their grades are plotted against the grades in their first course in Figure 1. The grading scale ranges from 0 to 4 , with 0 being an $\mathrm{E}$ and 4 an $\mathrm{A}$. There is a weak correlation between the two grades.

Of the 125 students who completed the conventional sections listed in Table 1, 44 completed a second thermodynamics course. Their grades are plotted in Figure 2 against the grades in their first course. There is little correlation between the two grades.

The 7 students who took the online section have a mean grade of 3.16 in their subsequent thermodynamics course. The 44 students who took the conventional section have a mean of 3.08. The statistically insignificant difference between the two means is $0.075 \pm 0.832$ (95\% confidence level). The t-distribution was used to calculate the confidence interval. 


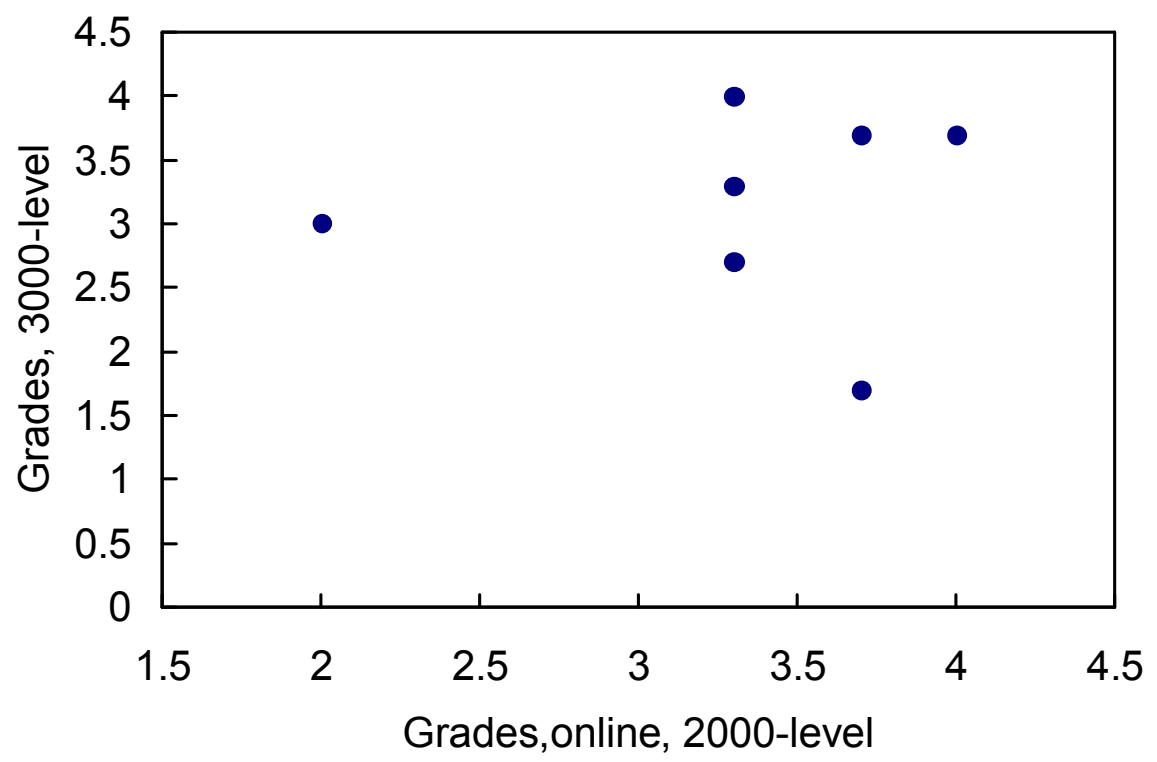

Figure 1. Of the 61 students who completed the online sections listed in Table 1, only 7 completed a second thermodynamics course. Their grades are plotted here against the grade they received in their first course.

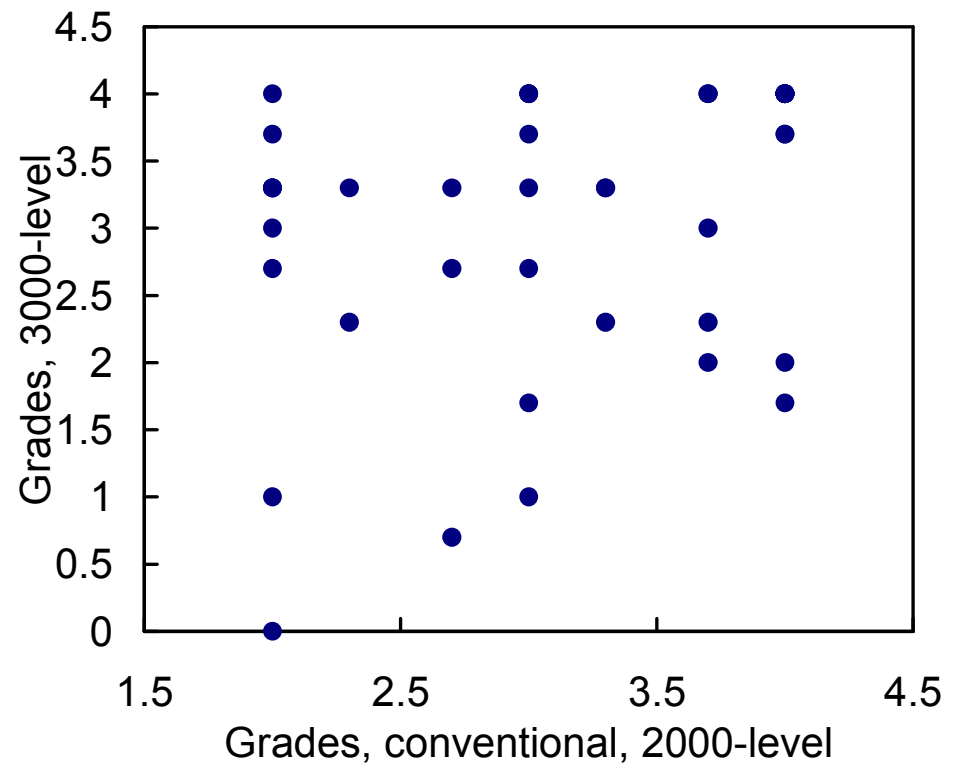

Figure 2. Of the 125 students who completed the conventional sections listed in Table 1, 44 completed a second thermodynamics course. Their grades are plotted here against the grade they received in their first course. 


\section{Comparison of Examinations and Grades}

The online and conventional sections take their examinations on different days. Two examinations were prepared to prevent giving an advantage to the second group. During Fall Semester 2001, however, I gave the sections different hour exams but identical finals. I tried this once. The statistics for the identical finals are summarized in Table 2. The two sections performed similarly. There were 21 students in the online section and 59 in the traditional.

\begin{tabular}{|l|l|l|}
\hline & $\begin{array}{l}\text { Conventional } \\
\text { section }\end{array}$ & $\begin{array}{l}\text { Online } \\
\text { section }\end{array}$ \\
\hline Possible & 200 & 200 \\
\hline Mean & 145 & 144 \\
\hline High & 196 & 197 \\
\hline Low & 69 & 90 \\
\hline Median & 142 & 146 \\
\hline Standard Deviation & 31.6 & 34.0 \\
\hline Number taking final & 59 & 21 \\
\hline
\end{tabular}

Table 2. During Fall Semester 2001, the sections were given different hour exams, but identical finals. The statistics for the identical finals are summarized here.

One additional comparison is possible and that is based on grades. In making this comparison I have focussed on those $\mathrm{ChE}$ and $\mathrm{ME}$ students who took subsequent thermodynamics courses. The 7 online students have a mean grade of 3.33 in the 2000level course. The 44 conventional students have a mean of 3.16. The statistically insignificant difference between the two means is $0.213 \pm 0.628$.

\section{General Observations Regarding the Online Format}

Thermodynamics is an abstract subject and most students find it challenging. I find it difficult to teach and I derive less pleasure from teaching it in the online format. I miss interacting with students in class.

The online format is convenient for students and it allows many to take a course that would otherwise not fit in their schedule. If you are thinking of developing an online course, I recommend that it be constructed from a traditional course and taught in parallel with it. I taught the conventional course twice before launching the online version. This allowed the development of homework solutions and lectures in an electronic format for use with the online course. The parallel approach enriches the traditional course with online materials and provides the instructor the reward of interacting with students in a classroom. 
About one month was required to convert my hand-written notes to PowerPoint slides. I avoided scanning hand-written notes because of the large file sizes that result. Most students studying at home do not have high-speed internet connections. All lectures, assignments, and solutions are posted in PDF format. Setting up the online quizzes in WebCT required about two weeks. Once the online materials are prepared, the time required to teach the online section is comparable to that for the conventional. The course materials are available at http://www.che.utah.edu/ geoff/thermol/index.html.

\section{References}

(1) Wallace, D.R. and P. Mutooni, "A Comparative Evaluation of World Wide Web-Based and Classroom Teaching," Journal of Engineering Education, Vol. 86, No. 3, 1997, pp. 211-219.

(2) Dutton, J., M. Dutton, and J. Perry, "Do Online Students Perform as Well as Lecture Students?" Journal of Engineering Education, Vol. 90, No. 1, 2001, pp. 131-136.

(3) Haag, S. and J.C. Palais, "Engineering online: Assessing Innovative Education," Journal of Engineering Education, Vol. 91, No. 2, 2002, pp. 285-290.

(4) Nguyen, J., and C.B. Paschal, "Development of Online Ultrasound Instructional Module and Comparison to Traditional Teaching Methods," Journal of Engineering Education, Vol. 91, No. 3, 2002, pp. 275-283.

\section{Biography}

GEOF SILCOX is Professor and Associate Chair of Chemical Engineering at the University of Utah (geoff@che.utah.edu). He teaches engineering thermodynamics and graduate heat transfer. His research interests are broad and include education, process modeling, and preventing and characterizing the emission of pollutants from the combustion of low quality fuels. 